\title{
一种基于碳纳米管/高分子复合材料的流量控制致动器
}

\author{
周智伟 $a, b$ 李庆威 ${ }^{a}$ 陈鲁倬 ${ }^{c}$ 刘长洪*, $a$ 范守善*,,$b$ \\ $\left({ }^{a}\right.$ 清华大学物理系 清华-富士康纳米科技研究中心 北京 100084) \\ ( ${ }^{b}$ 清华大学 材料学院 北京 100084) \\ ( ${ }^{c}$ 福建师范大学 物理与能源学院 福州 350007)
}

\begin{abstract}
摘要 利用超顺排碳纳米管/高分子复合材料设计和制造了一种半透明的流量控制致动器. 这种致动器能够像阀门一 样工作，展示了一种新颖的不需要沉重的机械传动装置就可以实现流体流速控制的方法. 通过电功率(或电压)能够实 现对流体流速的精确控制, 或者截断流体. 透过半透明的致动器壁, 能够清晰的观察到流量控制的过程. 这个致动器 具有低驱动电压 $(<6 \mathrm{~V})$, 良好的生物兼容性，良好的柔性和长的使用寿命(5000 次循环以上)等优点, 在仿生领域具有 广阔的应用前景.

关键词＼cjkstart碳纳米管; 复合材料; 致动器; 流量控制; 电热
\end{abstract}

\section{A Flow-controllable Actuator Made of Carbon Nanotube-polymer Composite}

\author{
Zhou, Zhiwei $^{a, b} \quad$ Li, Qingwei $^{a} \quad$ Chen, Luzhuo $^{c} \quad$ Liu, Changhong ${ }^{*, a} \quad$ Fan, Shoushan*,a,b \\ $\left({ }^{a}\right.$ Tsinghua-Foxconn Nanotechnology Research Center and Department of Physics, Tsinghua University, \\ Beijing 100084, China) \\ $\left({ }^{b}\right.$ School of Materials Science \& Engineering, Tsinghua University, Beijing 100084, China) \\ ( ${ }^{c}$ Fujian Provincial Key Laboratory of Quantum Manipulation and New Energy Materials, College of Physics and Energy, \\ Fujian Normal University, Fuzhou 350007, China)
}

\begin{abstract}
A translucent flow-controllable actuator based on the superaligned carbon nanotube films and polymers has been designed and fabricated. The actuator serves as a valve and shows an inspiring concept of controlling the fluid flow without heavy mechanical transmission devices. The flow can be precisely controlled or even shut off by the heating power (or applied voltage), and the process can be clearly observed through the translucent actuator wall. Owing to the advantages of low driving voltage $(<6 \mathrm{~V})$, good biocompatibility, great flexibility and long service life ( $>5000$ cycles), the actuator will have great potential applications in the biomimetic field.

Keywords carbon nanotubes; composite materials; actuator; flow-controllable; electrothermal
\end{abstract}

\section{Introduction}

Actuator materials have been widely studied in the past decades. ${ }^{[1-5]}$ They can convert different types of energy, such as thermal energy, electric energy, light energy, to mechanical energy. ${ }^{[6 \sim 10]}$ The actuation can be induced by air pressure, electric field, light, solvent, and so on.$^{[9 \sim 12]}$ In some aspects, the artificial actuators have already exceeded the natural muscles. ${ }^{[1,13]}$ These energy conversions and muscle-like responses are very meaningful in many areas, such as artificial muscles, biomimetic applications, optical devices and sensors. ${ }^{[14}$ 16] Among them, electroactive polymers (EAPs) are intensively studied due to their superior performances such as simple fabrication process, easy operation, low cost and lightness. ${ }^{[15,16]}$ But the ultra-high driving force or electrolyte-indispensable environment largely challenge the widespread utilizations of the
EAPs. ${ }^{[17]}$ Recently, electrothermal actuators have attracted more attentions. They have overcome the two main disadvantages of the EAPs due to the low driving force $(<200$ $\left.\mathrm{V} \cdot \mathrm{m}^{-1}\right)$ and the electrolyte free operating condition. ${ }^{[18]}$ Nevertheless, the appearances of the existing electrothermal actuators are mostly U-shaped strip heaters and the deformations are almost the simple bending or curling. Besides the matrix actuation, the electrothermal air-expansion actuators have also been investigated. ${ }^{[19,20]}$ But the reported strain is very small $(2.4 \%$ length contraction or about $1 \mathrm{~mm}$ deformation) and the biocompatibility is very poor. ${ }^{[19]}$ Then, the pneumatic actuators can give various muscle-like motions largely and rapidly due to the $3 \mathrm{D}$ printing technique. ${ }^{[21]}$ However, the heavy and complex equipment for the source of compressed gas restricts its further utilizations.

Carbon nanotubes (CNTs) have the advantages of good

\footnotetext{
* E-mail: chliu@mail.tsinghua.edu.cn; Tel: 62796011; fss-dmp@tsinghua.edu.cn Received July 15, 2016; published August 24, 2016.

Supporting information for this article is available free of charge via the Internet at http://sioc-journal.cn

Project supported by the National Basic Research Program of China (No. 2012CB932301) and the Natural Science Foundation of China (Nos. 51572146, 51502151 and 51202031).

项目受国家重点基础研究发展计划(No. 2012CB932301)和国家自然科学基金(Nos. 51572146, 51502151 and 51202031)资助.
} 
conductivity, flexibility, chemical and thermal stability, ${ }^{[22 \sim 24]}$ so they are mostly used in the electrothermal actuators. Polymers have the advantage of good biocompatibility, ${ }^{[25]}$ so they are the good candidates for the actuator matrices that provide proper strains and high stress. The CNTs/polymer composites have absorbed the advantages of the CNTs and the polymers, ${ }^{[18,26 \sim 29]}$ so they are widely discussed in the actuators in order to achieve the muscle-like responses. But the configurations of the reported actuators are monotonous and few complex devices have been developed. ${ }^{[18,20]}$ Thus, the practical applications are still very rare.

In this work, we introduce a translucent flow-controllable actuator (valve) made of the superaligned carbon nanotube (SACNT)/polymer composite. The working mechanism of the actuator is the air expansion and contraction resulting from voltage on and off. By adjusting the heating power (or applied voltage), the electrolyte-free actuator can control the fluid-flowing velocity rapidly and precisely without the heavy mechanical transmission devices, and the control process can be clearly seen through the translucent wall of the actuator. A flow speed of 7.25 $\mathrm{mL} \cdot \mathrm{s}^{-1}$ from a $250 \mathrm{~mm}$-high container (water level 150 $\mathrm{mm}$ ) can be easily shut off in $12 \mathrm{~s}$ while the driving voltage can be as low as $6 \mathrm{~V}$. Due to the good biocompatibility, flexibility and easy processing of the composites and the actuator, various configurations can be further designed to meet the applications in the complex environment of the human body, especially in the biomimetic fields.

\section{Results and Discussion}

\subsection{The characteristics of the SACNT/polymer com- posites}

The SACNT sheet can be drawn from the "CNT forest" continuously due to the van der Waals force. ${ }^{[30 \sim 32]}$ For the translucent actuator, 4 SACNT sheets were directly stacked on the pre-cured polymer matrix (SG3010), as shown in Figure 1a. The fabrication details are shown in the Experimental section. After final curing, the homogenous SACNT sheets were still orderly arrayed along the aligned direction, and the carbon nanotubes were well infiltrated by the polymer and can hardly be peeled off, as shown in Figure 1b. Thus, the composite surface (CNT side) could generate homogenous Joule heat while it was induced by the voltage.

As the actuator is driven by the Joule heat generated from the composite, it is important to know the ohmic characteristics of the composites. The SACNT film thickness, the CNT aligned direction and the infiltration degrees with the polymer are the main factors that affect the resistances of the composites. Figure $2 \mathrm{a}$ shows the relation-

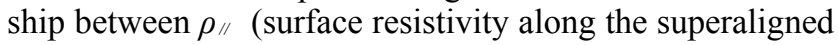
direction of the CNT) and the film layer (sheets) number. $\rho_{\text {/ }}$ drops rapidly from $227.2 \Omega$ to $1.6 \Omega$ as the layer number increases from 4 to 1000 . The surface resistivity perpendicular to the superaligned direction $\left(\rho_{\perp}\right)$ has the same variation tendency with the film layer number. It drops rapidly from $2212.9 \Omega$ to $11.0 \Omega$ as the layer number increases from 4 to 1000 , as shown in Figure $2 b$. Due to the (a)

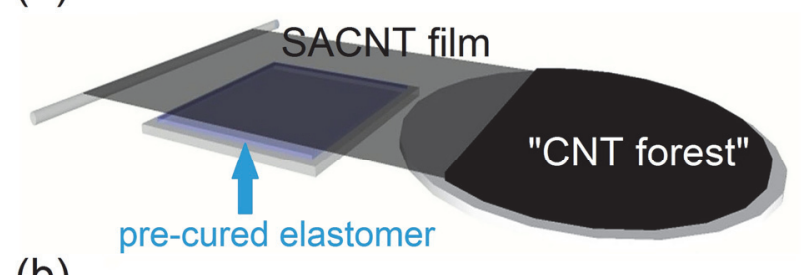

(b)

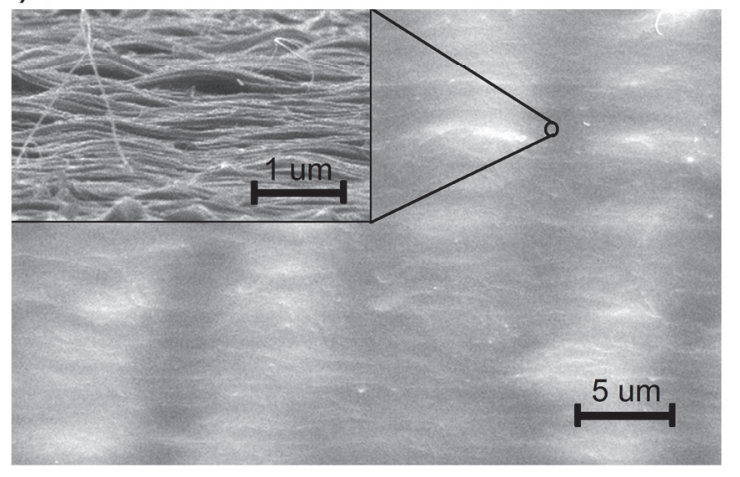

Figure 1 (a) Fabrication of the 4 SACNT sheets/polymer composite (repeat 4 times). (b) SEM images of the surface of the SACNT/polymer composite.

anisotropic conductivity of the SACNT, $\rho_{\perp}$ is much larger than $\rho_{/ /}$, such as $\rho_{\perp}$ is $97.3 \Omega$ while $\rho_{\text {/ }}$ is $10.6 \Omega$ for a 100 -layer SACNT film/SG3010 composite. In the composite, the SG3010 mixture covers the CNTs, so the conductivity of the CNTs has been reduced by the SG3010. When the SACNT and the partially cured SG3010 precursor were touched together, the precursor with a deeper curing degree infiltrated the CNTs with a less amount, so the resistance of the composite was smaller. The pre-curing time of the SG3010 at $80{ }^{\circ} \mathrm{C}$ was used to describe the pre-curing degree. Figure $2 \mathrm{c}$ and $2 \mathrm{~d}$ show the relationship between surface resistivity and the pre-curing time of the polymer matrix (the SACNT film layer number is 30). While pre-curing time is $0 \mathrm{~s}, \rho_{/ /}$and $\rho_{\perp}$ are 70.3 and 1098.3 $\Omega$, respectively. $\rho_{/ /}$and $\rho_{\perp}$ drop to 35.0 and $702.3 \Omega$ as the pre-curing time increases to $60 \mathrm{~s}$. Every point in Figure 2 is the average valve of three samples, and the valve differences between these three samples are less than $3 \%$. In brief, a thicker CNT film with a smaller infiltration degree in the aligned direction will make a lower resistivity of the composite. The surface resistivity $(\rho)$ of the composite can range from 1.6 to $2200 \Omega$ by controlling these three parameters during the fabrication process.

The transparence of the composite is also affected by the SACNT film layer number. Figure $3 \mathrm{a}$ shows the optical images of the composites with different SACNT film layer number. The transparence of the composite decreases with the increasing layer number of the SACNT film. When the layer number exceeds 10 , it is hard to see the things behind them. The transmittance of the composite has been tested by the spectrophotometer $(1 \mathrm{~mm}$ thickness transparent SG3010 film as the comparison substrate). Figure $3 \mathrm{~b}$ shows the transmittance spectra of the composites with different SACNT film layers. Figure 3c shows the transmittance values of the composites with different SACNT film layers at wavelength of $550 \mathrm{~nm}$. The transmittance of 

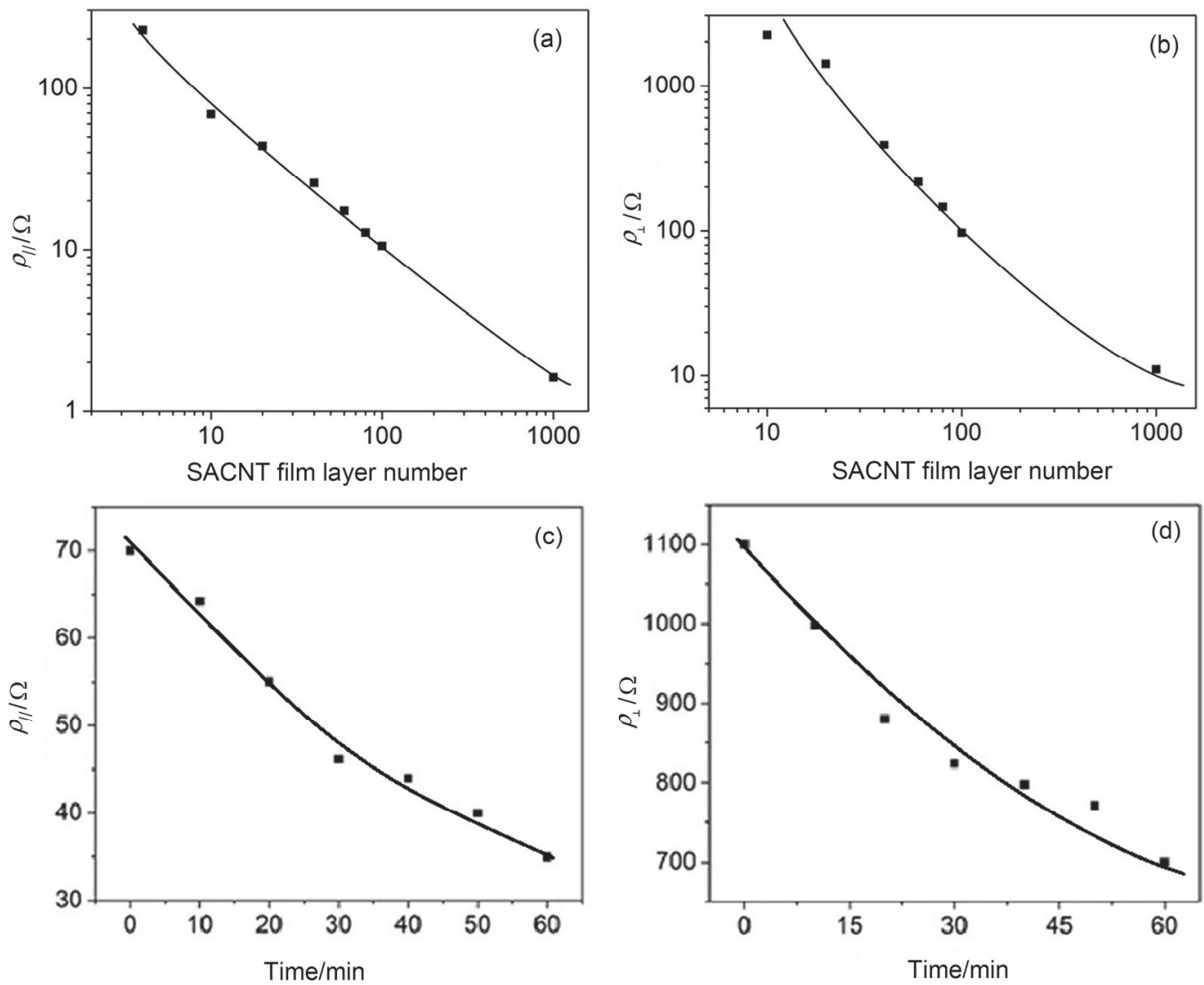

Figure 2 The ohmic characteristics of the composites. (a) and (b) The relationship between the surface resistivity and the SACNT film layer number. (c) and (d) The relationship between the surface resistivity and the pre-curing time of the polymer.

(a)

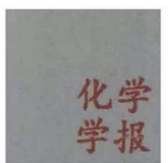

1

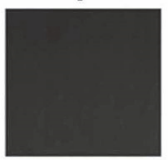

10

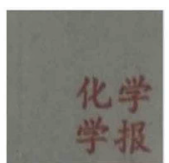

2

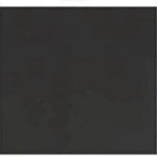

15

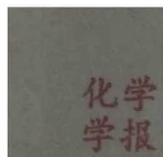

3

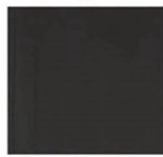

20

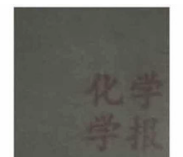

4

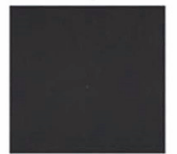

$30 \quad 1000$
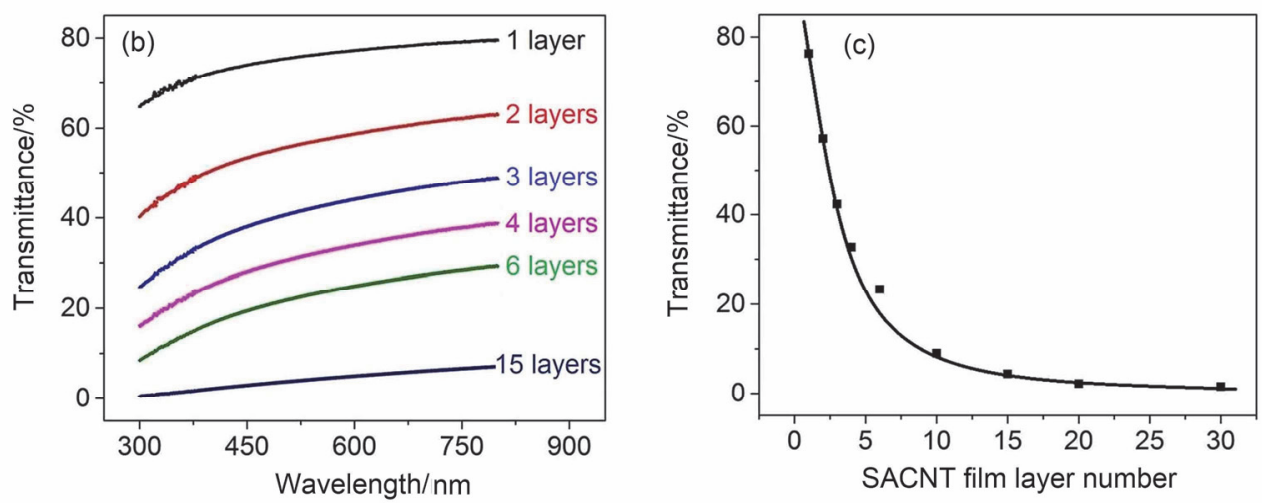

Figure 3 Light transmission properties of the composites. (a) Optical images of the composites with different SACNT film layer number. (b) Transmittance spectra of the composites with different SACNT film layers. (c) Transmittance values of the composites with different SACNT film layers at wavelength of $550 \mathrm{~nm}$. 
the 1-layer SACNT sheet/SG3010 composite is $76.3 \%$, and the composite is almost opaque (less than $10 \%$ in transmittance) while the SACNT sheets number exceeds 10 . Transparent or translucent actuators are more desirable in some cases, especially the inner working process needs to be detected, but the majority of the existing actuators are mostly opaque. Here, a 4-layer SACNT film/SG3010 composite was chosen due to its proper transmittance $(32.7 \%$ at the wavelength of $550 \mathrm{~nm})$ and surface resistivity $(227.2 \Omega)$.

\subsection{The characteristics of the flow-controllable valve}

Based on the performances and basic parameters of the SACNT/silicone elastomer heater, we can choose the proper configuration and related parameters for the flow-controllable actuator. The inner hollow tube has two open ends which allow liquid to pass through. The working mechanism of the actuator is the gas expansion and contraction. While the chamber is electrically heated, the closed air will expand. The outer tube (SG3010) is much stronger than the inner tube (Ecoflex), so the inner tube is pushed inwards and squashed by the increasing air pressure. Finally, the fluid flow passage (inner tube) is completely closed. The actuation speed is greatly affected by the heating power. The outer tube of the translucent actuator is made of the 4-layer SACNT composite, and the resistance of the embedded heater is about $250 \Omega$. As the voltage is on, the increased air pressure squeezes the inner tube more and more until it is totally closed. At $18 \mathrm{~W}$, it takes $25 \mathrm{~s}$ for the expanding air to shut the inner tube during the first cycle, and then $10 \mathrm{~s}$ is enough to shut the inner tube again after a $90 \mathrm{~s}$ recovery. Optical images of the front and side views show the actuation process (Figure 4). Due to the transparency of the outer tube, the changes of the inner tube can be observed by eyes. The temperatures of the outer tube wall are $22.4,36,144,22.4{ }^{\circ} \mathrm{C}$ in Figure $4 \mathrm{a} \sim 4 \mathrm{~d}$, respectively.

Two rubber tubes (outside diameter: $8 \mathrm{~mm}$, inner diameter $6 \mathrm{~mm}$ ) are connected to the both ends of the inner tube of the valve, and the joints are sealed by the Ecoflex. As one rubber tube is connected to a $250 \mathrm{~mm}$ higher container (water level: $150 \mathrm{~mm}$ ), the water can flow through the valve smoothly. When the valve heater is working, the expanding chamber air will squeeze the inner tube to slow down the flow speed. In order to cut off the water flow driven by the $400 \mathrm{~mm}$-high water pressure efficiently, 2.5 $\mathrm{mL}$ extra air has been injected into the chamber. Normally, it takes $124 \mathrm{~s}$ for $900 \mathrm{~mL}$ water to pass through the valve without the heating power, so the water speed is $7.25 \mathrm{~mL}$ • $\mathrm{s}^{-1}$. When the heater works at $40 \mathrm{~W}$, the water flow speed decreases gradually to zero within $17 \mathrm{~s}$, and then it takes $12 \mathrm{~s}$ to shut off the water flow again after a $40 \mathrm{~s}$ recovery. The working process of the flow-controllable valve can be clearly detected through the translucent wall, as shown in Figure $5 \mathrm{a} \sim 5 \mathrm{c}$ (blue water was used for a clearer display). In Figure $5 c$, there is no blue water in the inner tube, which means the water flow is totally shut off. In fact, the cyclic process has been tested for more than $70 \mathrm{~h}$ (5000 cycles), and the valve can still work properly as before. As shown in Figure S1, the water amount passed through the valve was stable (about $100 \mathrm{~mL}$ in each cycle) during the cyclic process, indicating its good repeatability and long service (a)

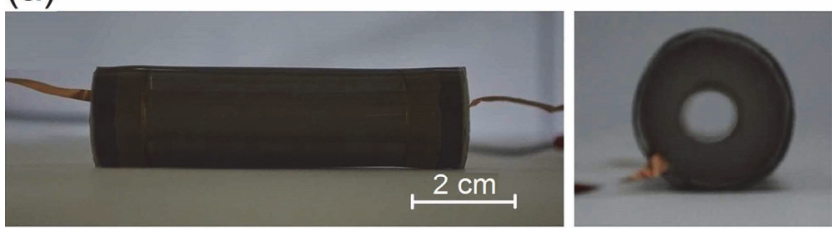

(b)
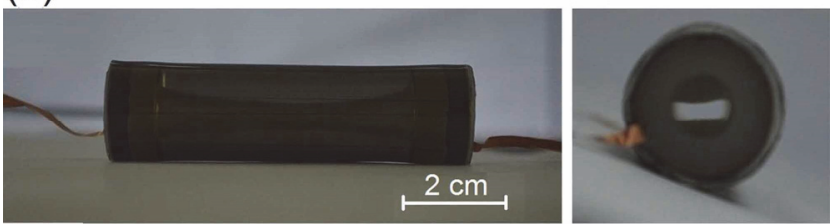

(c)
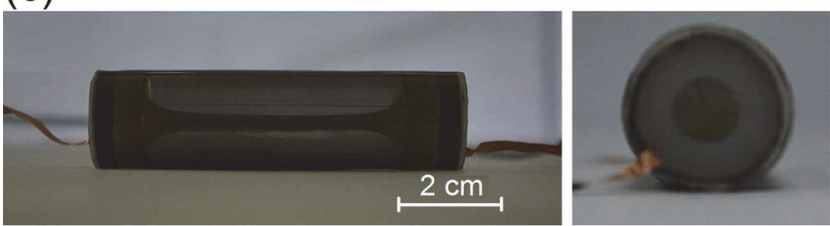

(d)
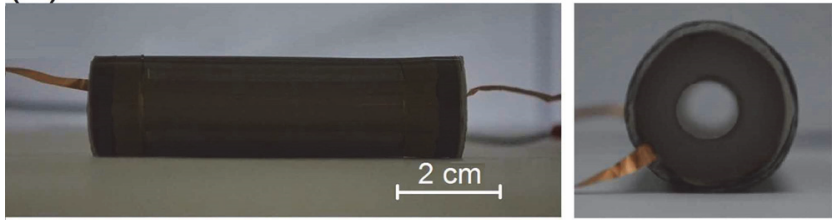

Figure 4 Front views and side views of the air valve. (a) Open state without applied voltage. (b) Partial closure during the process. (c) Complete closure of the valve. (d) Back to the initial state.

life. At different heating powers, the times of shutting off water flow are different, such as $12 \mathrm{~s}$ at $57.6 \mathrm{~W}$ or $80 \mathrm{~s}$ at 19.6 W. As shown in Figure 5d, the time cost decreases quickly as the heating power increases. When the heating power is below $18 \mathrm{~W}$, the valve can't shut off the flow any longer. However, the flow speed can be precisely controlled by the heating power even if the power is below 18 $\mathrm{W}$. The water flow will be stable under a certain power in tens of seconds. From 0 to $18 \mathrm{~W}$, a higher power leads to a slower flow speed, such as $4.5 \mathrm{~mL} \cdot \mathrm{s}^{-1}$ at $3.6 \mathrm{~W}$ or 1.3 $\mathrm{mL} \cdot \mathrm{s}^{-1}$ at $14.4 \mathrm{~W}$, as shown in Figure 5e. If the heating power is lower than $2 \mathrm{~W}$, the little variation of the air pressure will not affect the water flow. Every data point in Figure $5 \mathrm{~d}$ and $5 \mathrm{e}$ has been tested several times, and they are almost the same, which indicates the valve works stably. According to Figure 2, if the maximum input voltage or current is restricted by the input devices, the SACNT films with different alignments, different layers or different infiltration degree can be chosen to meet the appropriate heating power. If the 1000-layer SACNT composite is used in the valve, the control of the water flow can be achieved at an ultralow voltage $(6 \mathrm{~V}$ for $20 \mathrm{~W})$.

There are several advantages of the SACNT based flow-controllable valve. Firstly, as the superaligned carbon nanotube film composites are flexible, compliant, stable, of high strength and easy for processing, the valves with various configurations can be easily fabricated. Secondly, our $\mathrm{SACNT} /$ polymer heater can be shaped flexibly and placed 

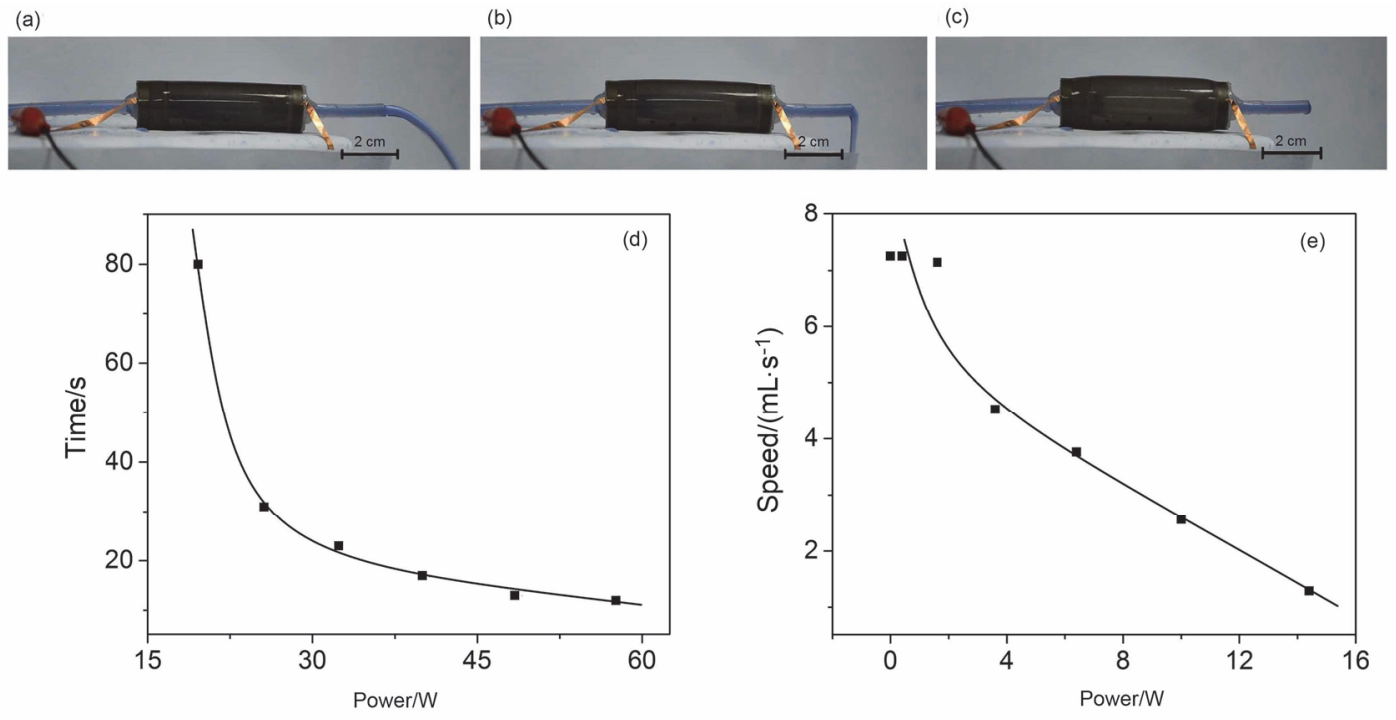

Figure 5 Characteristics of the flow control valve. (a) (c) Optical images for showing the control of the water flow as the voltage is on. (d) Different time is needed for the valve to shut off the water flow under different heating power. (e) The relationship between the water speed and the heating power (stable states).

properly. Thirdly, the resistance of the SACNT/polymer heater can be adjusted through several means (film thickness, CNT aligned direction, component infiltration degree) to meet different using conditions. Lastly, the translucent wall also allows us to observe and detect the inner working conditions directly. In addition, the flow-controllable valve shows a new approach to control the blood speed. The valve is made of the polymers, indicating their potential biological compatibility. The inner tube can be regarded as the blood vessel, and the expansion of the chamber air can be used to control the blood speed. Actually, the blood vessel is much smaller and the wall is much thinner than the inner tube of the valve, so it is easier to be squeezed or shut off. In our future work, we will try to twist a strip-shaped air-expansion actuator around the blood vessel for achieving an easy way of controlling the blood speed. The inner side clinging to the vessel is made of soft polymer, and the other side is made of high-strength polymer composite which also acts as a heater. We believe that if the valve can be miniaturized and biological compatible, it could be used to control the real blood speed at an ultralow voltage, and it will be demonstrated in our future works.

\section{Conclusions}

In summary, we have designed and fabricated a flow-controllable actuator (valve) from the SACNT/polymer composite. They have the advantages of lightweight, easy fabrication, easy operation and long life-time. The actuator can control the water flow precisely at an ultralow voltage $(<6 \mathrm{~V})$, which shows a novel approach of flow control without heavy mechanism devices. The control process can be clearly detected through the translucent actuator body. By further design and optimization, we believe that the flow-controllable actuator will show inspiring potential applications in various areas, and especially in the biomimetic fields.

\section{Experimental}

\subsection{Fabrication of the SACNT/polymer composites}

The SACNT sheet can be drawn from the "CNT forest" continuously due to the van der Waals force. ${ }^{[30 \sim 32]}$ By using a programmed machine, the sheet can be stacked on a frame layer by layer to shape a SACNT film. For the translucent actuator, 4 SACNT sheets were directly stacked on the pre-cured matrix (a high-strength elastomer from Beijing Hangtongzhou Technology Co., Ltd. China, $1 \mathrm{~h}$ at $80{ }^{\circ} \mathrm{C}$ ) to fabricate the composite (heater), as illustrated in Figure 1a. The final curing of the composite was another 1 h at $80{ }^{\circ} \mathrm{C}$.

\subsection{Fabrication of the flow-controllable actuator}

The actuator (valve) was constituted of two concentric hollow tubes. The outer tube was made of the SACNT/SG3010 composite while the inner tube was made of the Ecoflex (an ultra-soft elastomer), and the space between the tubes was sealed by the Ecoflex. The inner and outer tubes had the diameters of $10 \mathrm{~mm}$ and $20 \mathrm{~mm}$ respectively and had the same thickness $(1 \mathrm{~mm})$ and length $(70 \mathrm{~mm})$. The chamber length was $60 \mathrm{~mm}$, so the volume of the chamber was about $10.5 \mathrm{~mL}$. Figure $4 \mathrm{a}$ is the optical image of the flow-controllable valve with electrodes.

\subsection{Measurements}

An infrared thermometer (Optris LS, from Optris $\mathrm{GmbH}$ ) was used for detecting the temperature variation. A spectrophotometer (Lambda 950 UV/VIS Spectrometer from PerkinElmer) was used for testing the transmittance of the composite.

\section{References}

[1] Mirfakhrai, T.; Madden, J. D. W.; Baughman, R. H. Mater. Today 2007, 10, 30 .

[2] Bar-Cohen, Y. P. I. Mech. Eng. G-J. Aer. 2007, 221, 553

[3] Blaž, Z. A. B. Z. Appl. Phys. Express 2013, 6, 21701. 
[4] Chen, P. N.; He, S. S.; Xu, Y. F.; Sun, X. M.; Peng, H. S. Adv. Mater. 2015, 27, 4982 .

[5] Wang, Z.; Shen, X.; Chen, X. Semicond. Opt. 2015, 36, 77. (王振禄, 沈雪瑾, 陈晓阳, 半导体光电, 2015, 36, 77).

[6] Ha, S. M.; Yuan, W.; Pei, Q.; Pelrine, R.; Stanford, S. Adv. Mater. 2006, 18,887 .

[7] Aliev, A. E.; Oh, J. Y.; Kozlov, M. E.; Kuznetsov, A. A.; Fang, S. L.; Fonseca, A. F.; Ovalle, R.; Lima, M. D.; Haque, M. H.; Gartstein, Y. N.; Zhang, M.; Zakhidov, A. A.; Baughman, R. H. Science 2009, $323,1575$.

[8] Lim, Z. H.; Sow, C. H. Adv. Funct. Mater. 2010, $20,847$.

[9] Zhou, Z.; Li, Q.; Chen, L.; Liu, C.; Fan, S. J. Mater. Chem. B 2016, 4, 1228.

[10] Zhou, Z.; Chen, L.; Liu, C.; Fan, S. Carbon 2016, 96, 672.

[11] Sun, X. M.; Wang, W.; Qiu, L. B.; Guo, W. H.; Yu, Y. L.; Peng, H. S. Angew. Chem. Int. Ed. 2012, 51, 8520.

[12] Lu, X.; Zhang, Z.; Li, H.; Sun, X.; Peng, H. J. Mater. Chem. A 2014, 2, 17272 .

[13] Madden, J.; Vandesteeg, N. A.; Anquetil, P. A.; Madden, P.; Takshi, A.; Pytel, R. Z.; Lafontaine, S. R.; Wieringa, P. A.; Hunter, I. W. IEEE J. Oceanic Eng. 2004, 29, 706.

[14] Martinez, R. V.; Glavan, A. C.; Keplinger, C.; Oyetibo, A. I.; Whitesides, G. M. Adv. Funct. Mater. 2014, 24, 3003.

[15] Baughman, R. H. Synth. Met. 1996, 78, 339

[16] Bar-Cohen, Y. J. Spacecraft Rockets 2002, 39, 822.

[17] Pelrine, R.; Kornbluh, R.; Pei, Q. B.; Joseph, J. Science 2000, 287, 836.

[18] Chen, L. Z.; Liu, C. H.; Hu, C. H.; Fan, S. S. Appl. Phys. Lett. 2008, 92, 263104.

[19] Liu, Q.; Liu, L. Q.; Kuang, J.; Dai, Z. H.; Han, J. H.; Zhang, Z. Nanoscale 2014, 6, 6932.
[20] Hu, Y.; Lan, T.; Wu, G.; Zhu, Z.; Tao, X.; Chen, W. Chem. Commun. 2014, 50, 4951.

[21] Mosadegh, B.; Polygerinos, P.; Keplinger, C.; Wennstedt, S.; Shepherd, R. F.; Gupta, U.; Shim, J.; Bertoldi, K.; Walsh, C. J.; Whitesides, G. M. Adv. Funct. Mater. 2014, 24, 2163.

[22] Kim, Y. A.; Muramatsu, H.; Hayashi, T.; Endo, M.; Terrones, M.; Dresselhaus, M. S. Chem. Phys. Lett. 2004, 398, 87.

[23] Ebbesen, T. W.; Lezec, H. J.; Hiura, H.; Bennett, J. W.; Ghaemi, H. F.; Thio, T. Nature 1996, 382, 54.

[24] Qiu, L.; Sun, X.; Yang, Z.; Guo, W.; Peng, H. Acta Chim. Sinica 2012, 70, 1523. (丘龙斌, 孙雪梅, 仰志斌, 郭文瀚, 彭慧胜, 化学 学报, 2012, 70, 1523.)

[25] Yue, X.; Tian, W.; Yang, J.; Ma, F.; Ren, Q. Acta Chim. Sinica 2007, 65, 367. (岳秀丽, 田文杰, 杨今朝, 马放, 任南琪, 化学学报, 2007, 65, 367.)

[26] Zhao, D.; Li, Z.; Liu, L.; Zhang, Y.; Ren, D. Acta Chim. Sinica 2014, 72, 185. (赵冬梅, 李振伟, 刘领弟, 张艳红, 任德财, 化学学报, 2014, 72, 185.)

[27] Gao, Z.; Tong, H.; Chen, J.; Yue, S.; Bai, W. Acta Chim. Sinica 2014, 72, 1175. (高珍珍, 佟浩, 陈建慧, 岳世鸿, 白文龙, 化学学 报, 2014, 72, 1175.)

[28] Chen, L.; Weng, M.; Zhou, Z.; Zhou, Y.; Zhang, L.; Li, J.; Huang, Z.; Zhang, W.; Liu, C.; Fan, S. ACS Nano 2015, 9, 12189.

[29] Li, Q.; Liu, C.; Lin, Y.; Liu, L.; Jiang, K.; Fan, S. ACS Nano 2015, 9, 409.

[30] Fan, S. S.; Chapline, M. G.; Franklin, N. R.; Tombler, T. W.; Cassell, A. M.; Dai, H. J. Science 1999, 283, 512.

[31] Jiang, K. L.; Li, Q. Q.; Fan, S. S. Nature 2002, 419, 801.

[32] Jiang, K. L.; Wang, J. P.; Li, Q. Q.; Liu, L. A.; Liu, C. H.; Fan, S. S. Adv. Mater. 2011, 23, 1154. 